\title{
Comparison and Analysis of CAPM and BAPM Models
}

\author{
$\mathrm{Xin}-\mathrm{Ke} \mathrm{Ju}$ \\ School of Economics and Management, Nanjing University of Science and Technology \\ Nanjing, 210094, P. R. China \\ leslieju@qq.com
}

\begin{abstract}
By means of theoretical and empirical analysis, the capital asset pricing model (CAPM) and behavior asset pricing model (BAPM) were evaluated. The time series regression and cross-sectional regression were established with the empirical data from Shenzhen and Shanghai stock markets in the last two years. Comparison of the empirical data between the last two years and the financial crisis as well as the comparison of empirical results among Shenzhen, Shanghai and Hong Kong stock markets were made. A widespread noise trader risk existed in Shanghai stock and Hongkong $H$ shares market in the last two years, but the noise trader risk was less in Shenzhen stock market. During financial crisis, the noise trader risk also existed in Shanghai and Shenzhen stock markets. There is no obvious correlation between noise trader risk and stock returns. The explanatory ability of behavior asset pricing model for stock excess returns is better than capital asset pricing model.
\end{abstract}

Keywords-CAPM; ВAPM; noise trader risk; excess returns, explanatory ability

\section{INTRODUCTION}

The financial asset pricing is one of the important issues of finance. It is also a key issue that needs solving from the capital asset pricing model (CAPM) and behavior asset pricing model (BAPM). Under the condition that all investors adopt Markowitz theory to invest, CAPM describes the formation of market equilibrium, by using a simple linear relationship between the expected assets returns and risk [1]. BAPM is the expansion of CAPM; BAPM describes ways of assets pricing based on interaction of rational investors and irrational investors (noise investors) [2]. Is BAPM better than CAPM definitely? What difference between the two models in theory and empirical analysis? These problems will be addressed in the following text.

In 1952, Markowitz proposed a mean-variance portfolio theory in his publication entitled "portfolio selection" [3-4]. Then the modern portfolio theory was built based on the mean-variance models, which stands for the birth of the traditional (standard) finance. Based on Markowitz's research, William Sharpe (1964) established a single-factor model and built CAPM [5]. CAPM has been regarded as a criterion of asset-pricing-model during the past half centuries. A lot of scholars attempted to relax the primitive hypothesis unceasingly and extended the static CAPM.

Shefrin and Statman (1994) brought forward BAPM, which challenged CAPM [6]. Later on, scholars improved
BAPM unceasingly. In empirical analysis, Vikash Ramiah and Sinclair Davidson (2001) suggested a dynamic volume index (DVI) in order to test BAPM [7]. Subsequently, Wei Dong (2003) applied DVI to test BAPM in Chinese stock market [8]. Henceforth, scholars have done researches from many perspectives. On the other hand, the indexes adopted by researchers have been more and more complicated and close to the reality.

\section{COMPARISONS OF CAPM AND BAPM}

\section{A. Theoretical Basis of CAPM and BAPM}

Mean-variance portfolio theory is one of the CAPM rationales. Besides, another rationale of CAPM is effective markets hypothesis. In effect markets, investors are rational. BAPM is born out of CAPM, and is the outcome of applying behavior finance theories into asset pricing theories of traditional finance. Shefrin and Statman (1994) brought information traders, noise traders and interactions of the two into the asset pricing frame, proposed the behavior asset pricing theory and established BAPM [6].

\section{B. Hypotheses of CAPM and BAPM}

The largest difference of hypotheses between the two models is whether or not there are irrational traders in a long term. In CAPM hypothesis, investors are supposed to have no cognitive bias and to care only about mean values and variance. Even if some investors are not rational, price can not be affected since investors deal with each other randomly and the irrational factors can be cancelled out The BAPM hypothesizes that investors are divided into two categories_-information traders and noise traders (irrational traders). Information traders are rational traders who behave strictly according to the CAPM hypothesis. The noise traders do not have a strict mean-variance perference, and their investment decisions can be easily affected by affection instead of rational recognition.

Theoretical formulas of CAPM and BAPM are as follows,

$$
\begin{aligned}
& E\left(r_{\mathrm{i}}\right)=r_{\mathrm{f}}+\beta^{\mathrm{C}}{ }_{\mathrm{i}}\left(E\left(r_{\mathrm{MC}}\right)-r_{\mathrm{f}}\right) \\
& E\left(r_{\mathrm{i}}\right)=r_{\mathrm{f}}+\beta^{\mathrm{B}}{ }_{\mathrm{i}}\left(E\left(r_{\mathrm{MB}}\right)-r_{\mathrm{f}}\right)
\end{aligned}
$$

Where $E\left(\mathrm{r}_{\mathrm{i}}\right)$ is the expected return of asset $i, r_{\mathrm{f}}$ is riskfree interest rate, $\beta^{\mathrm{C}}{ }_{\mathrm{i}}$ is the sensitivity index for changes of asset $i$ 's return to changes of market portfolio (market portfolio in traditional theory) return, $E\left(r_{\mathrm{MC}}\right)$ is the expected return of market portfolio (market portfolio in traditional theory), $\beta^{\mathrm{B}}{ }_{\mathrm{i}}$ is the sensitivity index for changes of asset $i$ 's return to changes of behavior market portfolio 
return, $E\left(r_{\mathrm{MB}}\right)$ is the expected return of the behavior market portfolio.

It should be noted that in order to make behavior market portfolio, Ramiah and Davidson (2002), two Australia finance economists, have brought forward dynamic volume index (DVI) [9],

$$
D V I_{t}=\frac{\sum\left(S_{i t} \times P_{i t}\right)}{\sum\left(S_{i 0} \times P_{i 0}\right)} \times I_{0}
$$

where $D V I_{\mathrm{t}}$ is dynamic volume index in time $t, S_{\text {it }}$ and $S_{\mathrm{i} 0}$ are the quantities of the issued stock $\mathrm{i}$ in market portfolio in time $t$ and time 0 respectively, $P_{\text {it }}$ and $P_{\mathrm{i} 0}$ are the prices of stock $i$ in time $t$ and time 0 respectively, $I_{0}$ is a adjustable factor.

\section{COMPARING THE EXPLANATION ABILITY OF CAPM AND BAPM}

\section{A. Method and Design}

According to Equation 1 and Equation 2, a linear regression analysis was performed by using Eviews 6.0. The sample data mainly come from the websites of stock exchanges and the Qianlong securities analysis software. The samples spans from March 31st, 2011 to March 31st, 2013, which is the latest data when I wrote this paper. Besides, another sample period was from March 31st, 2007 to March 31st, 2009, a period of latest financial crisis. An artificial dividing date was made for comparison, since there is no very definite time period about last financial crisis. The data between the periods of the latest financial crisis and of last two years were compared by using daily returns. The 3-month RMB benchmark deposit interest rates of financial institutions were used as risk-free interest rates. The SSE 50 Index, SZSE Component Index, and Hang Seng China Enterprises Index (H share index) were used as basic samples for analyzing. The shares whose data is missing too much in sample period were filtered out.

Shanghai composite index, Shenzhen composite index and Hang Seng index were adopted respectively as a traditional market index. For the calculations of behavior market portfolio returns, The SSE 50 Index, SZSE Component Index, and Hang Seng China Enterprises Index could replace the DVI in their respective market, since the constitution principles of these three indexes are similar to DVI and since measuring DVI directly is complicated. Therefore, the replacement is reasonable in a certain range.

\section{B. Data Regression}

The CAPM and BAPM were evaluated using the sample data and parameters $\beta^{\mathrm{C}}{ }_{\mathrm{i}}$ and $\beta^{\mathrm{B}}{ }_{\mathrm{i}}$ were obtained. According to the values of $\beta^{\mathrm{C}}{ }_{\mathrm{i}}$ and $\beta^{\mathrm{B}}{ }_{\mathrm{i}}$, the noise trader risk (NTR) would be predicted. NTR value is
$\mathrm{NTR}=\beta_{\mathrm{i}}^{\mathrm{C}}-\beta^{\mathrm{B}}{ }_{\mathrm{i}}$

The NTR was visually represented by the variations of standard $\beta$ in CAPM and behavior $\beta$ in BAPM, as shown in Fig. 1.

In a stock market, NTR represents a risk from noise traders in excess of a fundamental risk. As can be seen from Fig. 2, all the NTR values are positive in the last two years in Shanghai stock exchange (SSE), which represents that NTR does exist widely and which is in good agreement with the major reported results. On the contrary, NTR is negative in the last two years in Shenzhen stock exchange (SZSE), which represents that there is little noise

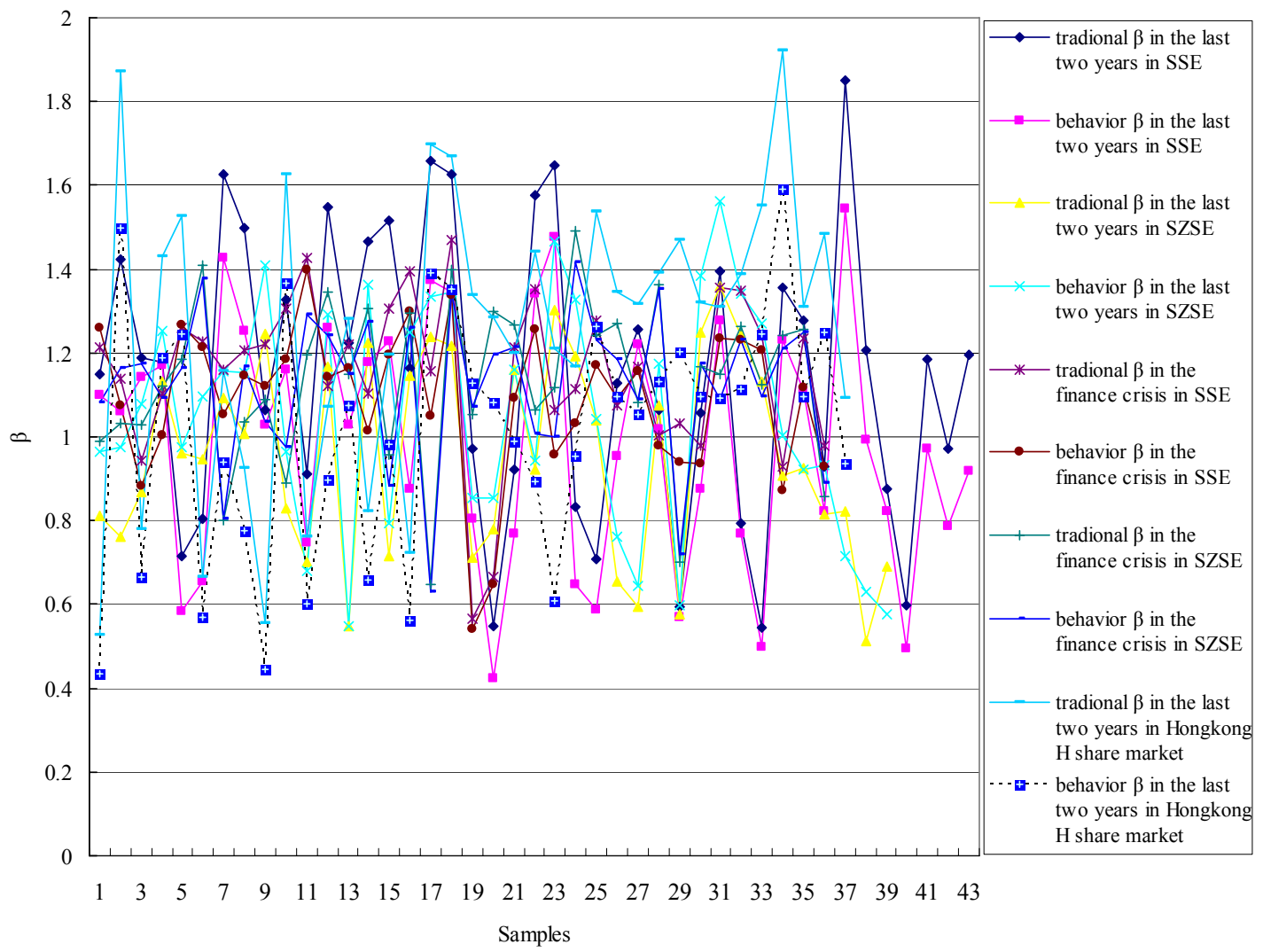

Figure 1. Variations of traditional $\beta$ in CAPM and behavior $\beta$ in BAPM in Shanghai, Shenzhen and Hong Kong H share markets 


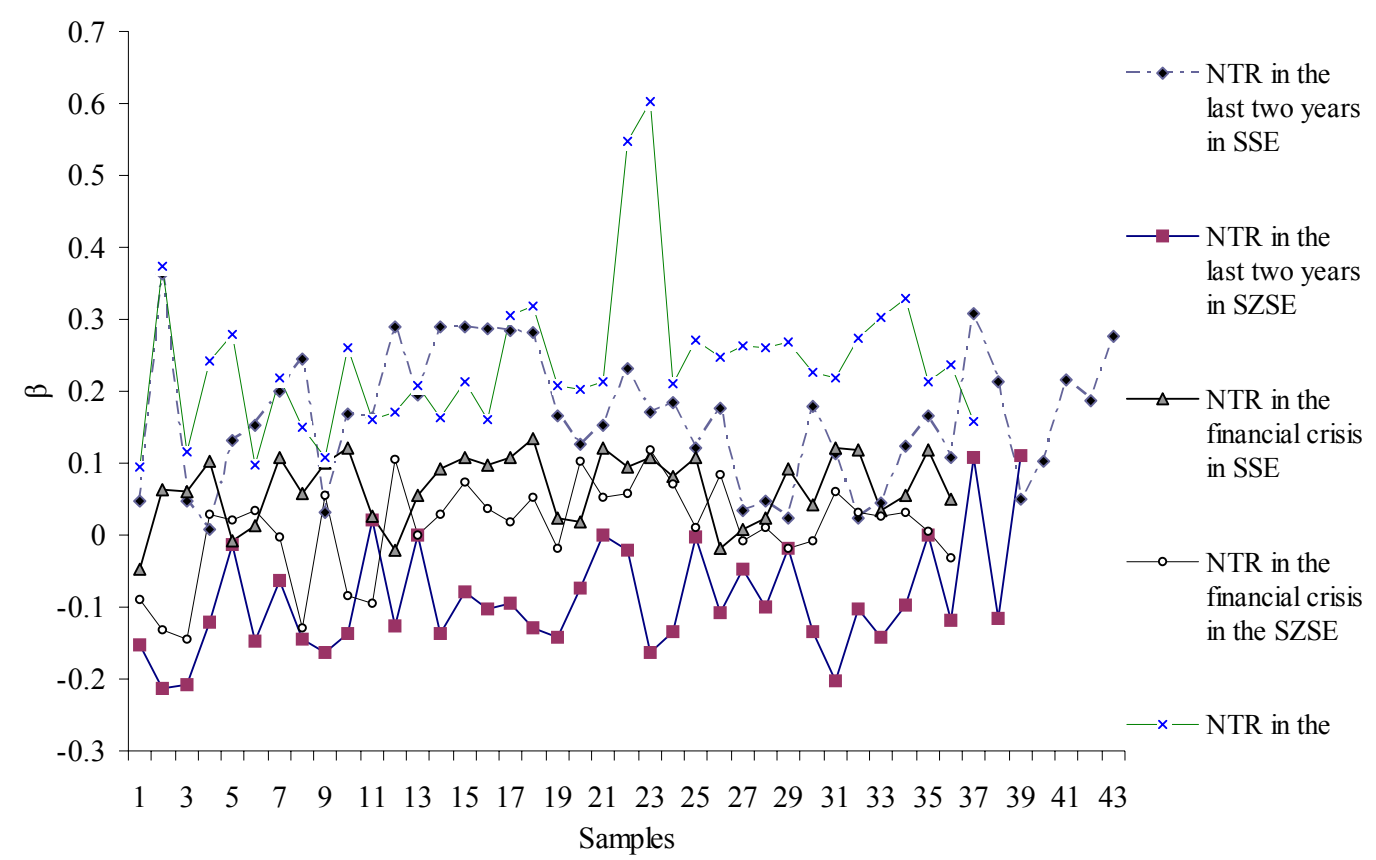

Figure 2. NTRs in different perods from different stock markets

trading risk in this market. The reasons may be the following:

Firstly, the replacement of DVI by Shenzhen composite index could not describe noise traders' behavior accurately. Secondly, the sample period is a fixed time period and the empirical analysis demonstrates that NTR is small in Shenzhen stock market from 2011 to 2013. The small NTR values cannot prove sufficiently that Shenzhen stock market is mature or NTR will not exist in the future in this market. Thirdly, Wang Jing and Zhang Ying (2006) empirically demonstrated that most stocks' NTRs are negative when lots of stocks are at low prices [10]. Although obvious falling trend did not exist in the Shenzhen stock market during the last two years, the fluctuations of the market are so frequent that there are several periods in which most stocks were at low prices. Probably it partly explains why NTR values are abnormal in Shenzhen stock market. The last but not least, it can be seen from the comparison of regression analysis between last two years and financial crisis period, that the market fluctuations are larger in financial crisis than in last two years. The market experienced a bull market before the crisis, a bear market and a market rebound afterwards. The NTR existed in Shenzhen stock market during financial crisis. Therefore, NTR values are relatively small when the stock market is relatively stable.

As shown in Fig 2, two characteristics are obvious: Firstly, NTR values in Shanghai stock market are very close to NTR values in Shenzhen stock market during financial crisis, and the regularity of data in the last two years is not obvious; Secondly, NTR values are larger in Hong Kong $\mathrm{H}$ shares market than in Shanghai stock market and in Shenzhen stock market.

\section{Correlations of NTR and Stock Excess Returns}

The stock excess return is the return rate on a stock relative to the return rate on risk free investment. Observations from SSE in the last two years were used after deleting those stocks whose data were absent too much during the sample period. As a result, a total of 337 trading day data were selected. The NTR is the explanatory variable and the stock excess return is the variable to be explained, and cross-sectional regressions were performed. When the free degree is 40 (The number of samples of SSE is 43 , therefore the free degree, $n-2$, is round down to 40.), the critical values of t are 1.684 and 1.303 , respectively, under significance levels of $5 \%$ and $10 \%$. Table 1 listed the statistic analysis of regression results.

Table 1 showed that NTR can either increase or decrease the stock excess returns. Therefore the correlation of NTR and stock excess returns is not significant. Meanwhile, for the total sample or the sample under significance levels of $5 \%$ or $10 \%$, the number of negative correlation sample is always slightly more than the number of the positive. This evidence indicates that it is a little higher possibility that NTR makes stock excess returns come down.

\section{Explanation Ability of Tradition $\beta$ and Behavior $\beta$}

In this part, the empirical data of Shanghai stock market in the last two years were used after deleting samples of trade suspension, and 337 business day data in total were chosen. By using tradition $\beta$ and behavior $\beta$ as the explanation variable, respectively, and stock excess returns as the variable to be explained, a cross-sectional regression was performed. As mentioned above, when the free degree is 40 , the critical values of $t$ are 1.684 and 1.303 , respectively, under significance levels of $5 \%$ and 
$10 \%$. The statistic analysis of regression results was collected in Table 2.

TABLE I. SAMPLE DISTRIBUTION FROM NTR RESULTS

\begin{tabular}{lccc}
\hline $\begin{array}{l}\text { Type of } \\
\text { correlation }\end{array}$ & $n^{*}$ & $|\mathrm{t}|>1.684$ & $|\mathrm{t}|>1.303$ \\
\hline $\begin{array}{l}\text { Negative } \\
\text { correlation }\end{array}$ & 179 & 81 & 102 \\
$\begin{array}{l}\text { Positive } \\
\text { correlation }\end{array}$ & 158 & 64 & 77 \\
\hline Number of sampling & & &
\end{tabular}

* Number of sampling

TABLE II. SAMPLE DISTRIBUTION UNDER DIFFERENT CONDITIONS

\begin{tabular}{|c|c|c|c|}
\hline Type of conditions & $\mathrm{n}^{*}$ & $|t|>1.684$ & $|t|>1.303$ \\
\hline $\begin{array}{c}\text { Coefficient of } \beta_{i}^{\mathrm{C}}> \\
\text { coefficient of } \beta^{\mathrm{B}}{ }_{\mathrm{i}}\end{array}$ & 162 & 45 & 61 \\
\hline $\begin{array}{c}\text { Coefficient of } \beta_{i}{ }_{i}< \\
\text { coefficient of } \beta^{B}{ }_{i}\end{array}$ & 175 & 40 & 66 \\
\hline $\begin{array}{c}\mathrm{t} \text { value of } \beta_{i}^{\mathrm{C}} \text { 's coefficient } \\
>\mathrm{t} \text { value of } \beta^{\mathrm{B}}{ }_{\mathrm{i}} \text { 's } \\
\text { coefficient }\end{array}$ & 153 & 36 & 50 \\
\hline $\begin{array}{c}\text { t value of } \beta_{i}^{\mathrm{C}} \text { 's coefficient } \\
<\mathrm{t} \text { value of } \beta^{\mathrm{B}}{ }_{\mathrm{i}} \text { 's } \\
\text { coefficient }\end{array}$ & 184 & 49 & 77 \\
\hline
\end{tabular}

\section{CONCLUSION}

The main conclusions of this paper are following:

In Shanghai stock market, a large quantity of noise traders existed in the last two years, therefore a widespread noise trader risk (NTR) existed and the market was easily disturbed by noise traders. The NTR was smaller in Shenzhen stock market, but was larger in Hongkong $\mathrm{H}$ shares market in the last two years. During the financial crisis, the noise trader risk also existed in Shanghai and Shenzhen stock markets.

The correlation between noise trader risk and stock returns is not yet clear. Simultaneously, there is a large possibility that NTR can make stock excess returns come down.
On the same conditions, explanatory ability of behavior $\beta$ to stock excess returns is slightly stronger than that of tradition $\beta$ (standard $\beta$ ). This means the explanatory ability of BAPM model for stock excess returns is better than that of CAPM model.

There are inevitably some drawbacks of this paper anyhow. One had to replace DVI with market indexes since the measurements of dynamic volume index (DVI) are so complex and jumble, leading to DVI values slightly inaccurate. How to build DVI rationally is still a hot topic in the future.

\section{ACKNOWLEDGMENT}

The author thanks the Innovation Funding from the Graduate School of NJUST for financial support.

\section{REFERENCES}

[1] E. F. Fama and K. R. French. The Capital Asset Pricing Model: Theory and Evidence. Journal of Economic Perspectives, 2004, 18(3), 25-46

[2] M. Statman. Behaviorial Finance: Past Battles and Future Engagements. Financial Analysts Journal, 1999, 55(6), 18-27

[3] H. Markowitz. Portfolio Selection. The Journal of Finance, 1952, 7(1), 77-91

[4] S. F. Witt and R. Dobbins. (1979) The Markowitz Contribution to Portfolio Theory. Managerial Finance, 1979, 5(1), 3-17. DOI: 10.1108/eb013433

[5] W. F. Sharpe. Source. The Journal of Finance, 1964, 19(3), 425 442.

[6] H. Shefrin and M. Statman. Behavioral Capital Asset Pricing Theory. Journal of Financial and Quantitative Analysis, 1994 29(3), 323-349

[7] V. Ramiah and S. Davidson. Behavioral aspects of finance: BAPM vs CAPM and noise traders' risk. Sydney: 14Th Australasian Finance and Banking Conference, 2001.

[8] X. G. Lu, R. Fu and D. Q. Lu. Prime Journal of Business Administration and Management 2012, 2(3), 474-484

[9] V. Ramiah and S. Davidson. Quantifying Noise Trader Risk: Noise-Adjusted Asset Pricing Model (NAPM). Understanding Overreaction, Underreaction and First Degree Irrationality. Seminar presentation, RMIT Melbourne, 2002

[10] Z. G. Sun. Owing to Behavior Asset Fixed Price Model ShanghaiShenzhen Exponent Demonstration Studies. Qingdao: Dissertation of Qingdao Universtiy, 2011

[11] J. Wang and Y. Zhang. Research on Applicability of Behavioral Asset Pricing Model. Value Engineering, 2006, 25(1), 119-122 